\title{
ACCURACY OF 24-HR FOOD-REGISTRY METHOD IN ELDERLY SUBJECTS: ROLE OF A SURROGATE RESPONDENT
}

\author{
J. Pardio ${ }^{1}$, P. Arroyo ${ }^{2}$, A. Loría ${ }^{3}$, S. Torres-Castro' ${ }^{2}$ M. Agudelo-Botero², \\ B.L. Jiménez Herrera ${ }^{4}$, A.T. Serrano Miranda
}

\begin{abstract}
Importance: There are problems in the dietary assessment of elders due to the aging process. Objective: To assess the comparativity of dietary diversity reported by an elder with that reported independently by his/her Caregiver. Design: Comparison of foods consumed by elder in the previous 24-h reported by elder and caregiver. Outcome variable: $\%$ of foods reported and unreported by either. Setting: A Housing Development Unit, and a Geriatric Rehabilitation Clinic. Participants: 26 elders of 65-94 years of age, plus 26 caregivers. Results: The \%foods unreported was more than double in elders than in caregiver (37\% vs 17\%). Regression models using sociodemographic variables of elders and caregivers as predictor variables showed only one significant variable [Caregiver cooked for the elder] associated with \%unreported by caregiver and with \%reported by either. No association with age, sex, being next-of-kin, schooling, cognitive level or setting was observed. Conclusion: The use of surrogates in dietary evaluation of elders should be carried out using the person in charge of preparing foods for the elder.
\end{abstract}

Key words: Elder, dietary assessment, surrogate respondent.

\section{Introduction}

Dietary assessment methods applied to elderly subjects present different sources of error, some of them related to the aging process itself $(1,2)$. Few studies have assessed the use and validity of dietary assessment methods in elderly people. One strategy has been to obtain the information on the elder's diet from surrogate respondents, especially close relatives. (3) The aim of the present study was to assess the comparability of the elder's information on dietary diversity obtained with a 24-Hr dietary recall method, with the independent report of the elder's Caregiver. The dietary information collected focused on the number of different food items consumed by the Elder, as well as the cooking method applied. The research model aimed at evaluating the independent influence of age, sex, formal education and level of cognitive performance of elders. Other independent variables analyzed were the caregiver's role in the elder's diet preparation, the study setting and whether the elder and caregiver were next-of-kin.

1. Fundación Mexicana para la Salud; 2. Instituto Nacional de Geriatría; 3. Instituto Nacional de Ciencias Médicas y Nutrición Salvador Zubirán; 4. Instituto Nacional de Rehabilitación Luis Guillermo Ibarra Ibarra

Corresponding Author: Pedro Arroyo, Instituto Nacional de Geriatria, Epidemiología Clínica, Blvd. Adolfo Ruíz Cortines 2767, Col. San Jerónimo Lídice, 10200 México, México, Distrito Federal 10200, Mexico, 52(55)60667222, pedro.arroyo95@gmail.com

\section{Methods}

The study comprised 26 Elders of $65+$ years of age, plus 26 Caregivers (CAREGIVERS). A CAREGIVER was defined as the accompanying person who had information on the diet consumed by the Elder the previous 24 hours. One inclusion criteria was that the three main meals the elder had the previous 24 hours had been consumed at home. Thirteen free living elders and caregivers were residents of a Mexico City Housing Development Unit belonging to the National Social Security Institute (IMSS-Unidad IndependenciaI) and the other 13 couples were contacted in the Geriatrics Rehabilitation Outpatients Clinic of a third-level Public Health Institution (Instituto Nacional de Rehabilitación).

Reported and unreported foods in the 24-hour recall method. The study comprised two interviews: the first one collected the study acceptance with text of an informed consent, as well as demographic and social variables. The Elder's cognitive level was assessed in this first interview. To register the dietary information, a second interview was programmed seven days later. No interviews were programmed during weekends. The recall method was applied to both Elder and CAREGIVER as to what foods the Elder had eaten the previous day; all-day food recording was divided in seven times. To prevent intrapair data contamination, the survey was always applied to one member of the 
pair in the absence of the other. The identity of each food eaten in the 24-hr period was recorded, thus integrating 26 paired diet reports of the Elder, one filled by the Elder him/herself and the other by his/her corresponding CAREGIVER.

Dietary diversity. This variable was the number of different foods consumed by the Elder the previous 24 hours. A different food was defined based on the type of ingredients and preparation techniques, independently of the food group in which the main ingredients were classified. The foods were classified as: a) Missed if only one member of the pair reported it but not the other, and the missing food was ascribed to the member who did not report it; and b) Reported if both members did so. The sum of foods missed by CAREGIVER, missed by Elder, and Reported by both was used as the $100 \%$ value to calculate the percentages of Missing and Reported foods ascribed to each member of the pair.

The survey was implemented by 4 well trained and standardized nutritionists. The cognitive status of elders was assessed with Pfeiffer's Short Portable Mental Status Questionnaire (4).

\section{Results}

Foods reported by the 26 Elder-CAREGIVER pairs. The total number of different foods reported by Elder and CAREGIVER in the $24-\mathrm{h}$ recall method ranged between 5 and 37 foods with a mean of 12.6. In regard to Missing foods, the proportion omitted by Elders was more than double the proportion in CAREGIVERS $(37 \%$ vs $17 \%$ ) with wide intrapair variation, i.e., 13 of the 26 Elders reported from $20 \%$ to $67 \%$ less foods than their corresponding CAREGIVER but four CAREGIVERS had a higher proportion of Missing foods than their corresponding Elder, and three pairs showed no intrapair difference.

Sociodemographic variables. Table 1 gives the descriptive statistics of 11 sociodemographic variables of Elders and CAREGIVERs. Nearly half of the CAREGIVERs cooked for the Elder and slightly more than half had blood ties with the Elder. There was an identical minority of men in Elders and CAREGIVERs, and a wide range in the age of CAREGIVERs due to the presence of three CAREGIVERs with ages above 60 . The 11 variables of Table 1 were used as predictor variables in the multiple regression models shown in Table 2.

Linear Regression Analysis. Table 2 shows the regression models corresponding to different dependent variables: the first two models used the \%Reported by Elders [Model 1] and by CAREGIVERs [Model 2] as the dependent variable. Models 1 and 2 were very similar with a single predictor variable (CAREGIVER cooks for Elder). This same predictor appeared in Model 4 that used \% Missing by CAREGIVER as the dependent variable, but not in Model 3 with \%Missing by Elder as the dependent variable. The coefficients of the factor
[CAREGIVER prepares food for Elder] were positive in Models 1 and 2 and negative in Model 4, indicating that cooking for the elder led to a $26-27 \%$ increase of Reported Foods in Models 1 and 2, and to a 14\% decrease in Missing Foods by the CAREGIVER in Model 4. In addition, sex of Elder and CAREGIVER showed associations in Model 4, i.e., less Missing Foods when Elder and CAREGIVER were males.

Table 1

Descriptive statistics of the variables used as independent variables in the multiple regression analysis of Table 2

\begin{tabular}{lll}
\hline Variable & Value & Proportion \\
\hline CAREGIVER cooks for Elder & Yes & $46 \%[12 / 26]$ \\
CAREGIVER kin of Elder & Yes & $54 \%[14 / 26]$ \\
Setting * & Rehab Center & $50 \%[13 / 26]$ \\
Sex Elder & Male & $27 \%[7 / 26]$ \\
Sex CAREGIVER & Male & $27 \%[7 / 26]$ \\
Variable & Range & Mean \pm SD \\
NDF & $5-37$ & $12.3 \pm 6.8$ \\
Age Elder & $67-97$ & $81.9 \pm 7.0$ \\
Age CAREGIVER & $27-77$ & $52.1 \pm 11.8$ \\
Schooling Elder ** & $0-5$ & $2.0 \pm 1.4$ \\
Schooling CAREGIVER & $0-4$ & $3.0 \pm 1.2$ \\
COG Elder *** & $2-10$ & $6.3 \pm 2.9$ \\
\hline
\end{tabular}

* Setting: participants visited at home vs those recruited at a Rehab Center; ${ }^{* *}$ Schooling had 6 categories ranging from 0 [can't read/write] to 5 [postgraduate]; ${ }^{* * *} \mathrm{COG}$ refers to a cognitive test score ranging from 0 [No errors] to 10 [All errors].

\section{Discussion}

A challenge for effective dietary assessment in older adults is to distinguish between those able to respond, and those who require adapted techniques. (1) Here we assumed that all elders interviewed were able to provide reliable information on the diversity of the diet consumed the previous 24 hours. The $24 \mathrm{~h}$-recall method and the semi qualitative evaluation of the dietary diversity were meant to overcome the limitations of the aged. The results showed that the proportion of Missed Foods was more than double in Elders versus his/her CAREGIVER $(37 \%$ vs $17 \%$, Table 1). In addition, the proportion of Reported Foods of both Elder and CAREGIVER was associated to whether the CAREGIVER cooked for the Elder or not. (Models 1 \&2, Table 3) Cooking for the Elder came out as the only significant decrease in the proportion of Missed Foods of the CAREGIVER. (table 3)

Thus, cooking for the Elder produced the lowest percentage of Missing Foods in the CAREGIVERS (median of 3\%), which suggests that surveys in the very old would not only require a surrogate but that the surrogate should be preferably one familiar with what 
Table 2

Multiple Regression Models using as dependent variable \% of foods Reported and Missed by Elder and Caregiver versus variables of table 2 as predictors

\begin{tabular}{|c|c|c|c|c|c|}
\hline \multirow[t]{2}{*}{ Model } & \multirow[t]{2}{*}{ Dependent variable } & \multirow[t]{2}{*}{ Predictive variable } & \multicolumn{3}{|c|}{ Regression data } \\
\hline & & & Coefficient & Beta & Sig \\
\hline 1 & $\%$ Reported by Elder & CG prepares food for Elder & 26.894 & 0.558 & 0.002 \\
\hline 2 & $\%$ Reported by CG & CG prepares food for Elder & 26.467 & 0.552 & 0.003 \\
\hline 3 & $\%$ Missed by Elder & None & - & - & - \\
\hline \multirow[t]{3}{*}{4} & $\%$ Missed by CG & CG prepares food for Elder & -14.466 & -0.552 & 0.002 \\
\hline & Sex of Elder & -11.126 & -0.378 & 0.025 & \\
\hline & Sex of CG & -8.556 & -0.29 & 0.081 & \\
\hline
\end{tabular}

Significant regression coeficcients were generated using a Backward method of multiple regression; Beta=Standardized coefficient. The eleven variables of table 2 were included as potential predictive variables.

Table 3

Median of the proportion of Reported Foods and Missed Foods according to whether the Caregiver prepared or did not prepare the food of the corresponding Elder

\begin{tabular}{lccccc}
\hline CG prepares food for Elder & N of pairs & Median of NDF* & $\begin{array}{c}\text { \% Reported by } \\
\text { both }\end{array}$ & $\begin{array}{c}\text { \% Missing } \\
\text { Elder }\end{array}$ & $\begin{array}{c}\text { Percentile 50 [P10-P90] } \\
\text { Caregiver }\end{array}$ \\
\hline Yes & 12 & 113 & $6 \%[5-71 \%]$ & $30 \%[5-63 \%]$ & $3 \%[0-32 \%]$ \\
No & 14 & 11.5 & $65 \%[40-95 \%]$ & $42 \%[15-68 \%]$ & $22 \%[9-41 \%]$ \\
U test & & NS 0.25 & NS 0.24 & NS 0.45 & Sig 0.036 \\
\hline
\end{tabular}

${ }^{*} \mathrm{NDF}=$ Number of different foods

the propositus eats.

We have no explanation as to why being male was associated to a significant decrease in the percentage of Missing Foods of Caregivers (Model 4, Table 2), especially as 12 pairs were of the opposite sex and only one was male-male and 13 were women-women. We had expected a larger proportion of Missing Foods in the opposite sex pairs as men are less familiar with foods and ingredients that go into a cooked meal.

It is worth commenting that our recall method was on different foods consumed by the Elder rather than the amounts ingested. We believe that making it qualitative increases the precision and reliability of the information as well as the fact that consumption was asked in seven times of the previous day [three meals and four in-betweens]. In addition, care was taken to apply the recall method to each member of the pair independently.

Neither cognitive level of Elder nor blood relationship between Elder and Caregiver were associated with percentages of Reported or Missing Foods. The data of Samet in his review of surrogate measures of dietary intake (3) cannot be compared with ours since it relied mostly on terminally ill patients with a short number of aged subjects. Also not comparable are the studies with the mother as informant in populations under 15 years. (5)

Our study suggests that surrogates would be necessary for elders. In countries like Mexico, in which the majority of Elders still live with their extended family, the best surrogate would be the person responsible for the preparation of foods, regardless of being or not nextof-kin. In 2010, $80 \%$ of elders older than 70 years lived with nuclear or extended families (6). In the case for the industrialized countries a significant proportion of elders live alone or in institutions.

Conflict of interest: J Pardío. No conflict of interest; P Arroyo. No conflict of interest; A Loría. No conflict of interest; S Torres-Castro. No conflict of interest; $\mathrm{M}$ Agudelo-Botero. No conflict of interest; BL Jiménez Herrera. No conflict of interest; AT Serrano Miranda. No conflict of interest.

Ethical standard: The informed and written consent was requested of both the elder and the CAREGIVER.

\section{References}

1. de Vries JHM, de Groot LCPGM, van Staveren WA (2009) Dietary assessment in elderly people: experiences gained from studies in the Netherlands. Eur Clin Nutr 2009;63:S69-S74

2. Ortiz-Andrellucchi A, Sánchez-Villegas A, Doreste-Alonso-de-Vries J, de Groot L, Serra-Majem L (2009) Dietary assessment methods for micronutrient intake in elderly people: a systematic review. Br J Nutr 2009;102:S118-S149.

3. Samet JM (1989) Surrogate measures of dietary intake Am J Clin Nutr 1989;50:1139-44.

4. Pfeiffer E (1975) A short portable mental status questionnaire for the assessment of organic brain deficit in elderly patients. J Am Geriatr Soc 1975;23:433-41.

5. Gutiérrez JP, Rivera-Dommarco J, Shamah-Levy T, Villalpando-Hernández S, Franco A, Cuevas-Nasu L, Romero-Martínez M, Hernández-Ávila M (2012) Encuesta Nacional de Salud y Nutrición 2012. Resultados Nacionales. Instituto Nacional de Salud Pública, México, 2012

6. Wong R, González González C, López Ortega M (2014) Envejecimiento y población en edades avanzadas. In: Rabell Romero C (Coord). Los mexicanos. Un balance del cambio demográfico, 1st edn. Fondo de Cultura Económica, México, 2014;pp 185-224. 